\title{
Distribution and isolation of strains belonging to the order Solirubrobacterales
}

\author{
Tamae Seki $^{1}$, Atsuko Matsumoto ${ }^{1,2}$, Satoshi Ōmura ${ }^{1}$ and Yōko Takahashi ${ }^{1}$ \\ The Journal of Antibiotics (2015) 68, 763-766; doi:10.1038/ja.2015.67; published online 1 July 2015
}

The number of prokaryotes on earth is estimated to be in the order of $10^{30}$ cells, ${ }^{1}$ and it is well known that most microorganisms in the environment are as-yet-uncultured. ${ }^{2}$ Many approaches have been tried to isolate unknown bacterial strains. Davis et al. ${ }^{3}$ reported that medium choice and incubation time are significant for isolation of rare soil bacteria. Patulibacter minatonensis, belonging to the order Solirubrobacterales, was isolated using medium supplemented with superoxide dismutase and proposed as a novel genus in $2006 .{ }^{4}$ At that time, the order Solirubrobacterales ${ }^{5}$ consisted of only three families, three genera and three species; Patulibacter minatonensis, Conexibacter woesei $^{6}$ and Solirubrobacter pauli, ${ }^{7}$ and presently there are still 11 species including the one species that is isolated in this study. We believe that as-yet-uncultured bacteria may exist within this taxon, and it is possible that additional strains could be used as an untapped resource. As the genera Patulibacter, Conexibacter and Solirubrobacter grow slowly, we tried to investigate their distribution and isolate them by cultivation over a long period of time in order to isolate strains belonging to the order Solirubrobacterales.

The strategy of detection and isolation of strains in the order Solirubrobacterales is shown in Figure 1. We designed specific primers for detecting Solirubrobacterales strains using the sequences of nine most closely related strains. The strains were as follows: Patulibacter minatonensis KV-614 ${ }^{\mathrm{T}}$, Conexibacter woesei DSM $14684^{\mathrm{T}}, 6$ Solirubrobacter pauli $\mathrm{B} 33 \mathrm{D} 1^{\mathrm{T}}, 7$ Rubrobacter radiotolerans $\mathrm{DSM} 5868^{\mathrm{T}}, 8$ R. taiwanensis LS-286, ${ }^{9}$ R. xylanophilus $\mathrm{PRD}-1^{\mathrm{T}},{ }^{10}$ Symbiobacterium toebii SC-1 ${ }^{\mathrm{T}}, 11$ Thermoleophilum album ATCC $35266^{\mathrm{TM}}$ and T. minutam ATCC $35268^{\mathrm{T}} .{ }^{2,13}$ These gene sequences were aligned to obtain specific sequences and then visually compared to identify regions showing a high degree of conservation within the target order. The primer length was adjusted to give an appropriate $T_{\mathrm{m}}$ range to minimize $T_{\mathrm{m}}$ differences within primer pairs. Specific primer sets for strains related to the order Solirubrobacterales were designed as follows: 423PF: 5'-TCAGTTGGGACGAAGCTTC-3' and 1012PR: 5'-AGG GAAGACGTGTTTCCAC-3'. PCR was performed initially with universal primers, and then nested PCR was performed for detection of target DNA in soil samples. PCR with universal primers $\left(11 \mathrm{~F}: 5^{\prime}-\right.$ AGTTTGATCATGGCTCAG-3', 1100R:5'-GGGTTGCGCTCGTTG-3' or 1115R:5'-AGGGTTGCGCTCGTTG-3') was performed as follows: initial denaturation at $95^{\circ} \mathrm{C}$ for $1 \mathrm{~min}$, followed by 30 cycles of denaturation at $95^{\circ} \mathrm{C}$ for $1 \mathrm{~min}$, annealing at $50^{\circ} \mathrm{C}$ for $1 \mathrm{~min}$, extension at $72^{\circ} \mathrm{C}$ for $1.5 \mathrm{~min}$ and an additional extension step at $72{ }^{\circ} \mathrm{C}$ for $2 \mathrm{~min}$. Reaction mixtures $(50 \mu \mathrm{l})$ containing $0.4 \mu \mathrm{l}$ of Taq polymerase (TaKaRa, Shiga, Japan), $5.0 \mu \mathrm{l}$ of $10 \times$ Taq buffer, $2.0 \mu \mathrm{l}$ of dNTP mixtures $(2.5 \mu \mathrm{M}), 29.6 \mu \mathrm{l}$ of $\mathrm{dH}_{2} \mathrm{O}, 4.0 \mu \mathrm{l}$ of each primer $(5 \mu \mathrm{M})$ and $5.0 \mu \mathrm{l}$ of DNA were prepared. As a second step, PCR with specific primers (423PF-1012PR) was performed as follows: initial denaturation at $94^{\circ} \mathrm{C}$ for $1 \mathrm{~min}$, followed by 30 cycles of denaturation at $94^{\circ} \mathrm{C}$ for $1 \mathrm{~min}$, annealing at $65^{\circ} \mathrm{C}$ for $1 \mathrm{~min}$, extension at $72^{\circ} \mathrm{C}$ for $1.5 \mathrm{~min}$ and an additional extension step at $72^{\circ} \mathrm{C}$ for $2 \mathrm{~min}$. Reaction mixtures (25 $\mu \mathrm{l}$ ) containing $0.2 \mu \mathrm{l}$ of Taq polymerase (TaKaRa), $2.5 \mu \mathrm{l}$ of $10 \times$ Taq buffer, $1.0 \mu \mathrm{l}$ of dNTP mixtures $(2.5 \mu \mathrm{M}), 14.3 \mu \mathrm{l}$ of $\mathrm{dH}_{2} \mathrm{O}$, $2.0 \mu \mathrm{l}$ of each primer $(20 \mu \mathrm{M})$ and $3.0 \mu \mathrm{l}$ of the first PCR products were prepared. The specific primers were tested using three genera belonging to the order Solirubrobacterales and specific bands of approximately $590 \mathrm{bp}$ were detected in P. minatonensis $\mathrm{KV}-614^{\mathrm{T}}$ and C. woesei NBRC $100937^{\mathrm{T}}$, but not in S. pauli JCM $13025^{\mathrm{T}}$. This result indicates that it was possible to detect strains related to them with some exceptions. Forty-four soil samples were collected from various environments in seven prefectures (Ibaraki, Saitama, Tokyo, Kanagawa, Chiba, Yamanashi and Okinawa) in Japan. Bacterial DNA was directly extracted from soil samples using a PowerSoil DNA Isolation Kit (MO BIO, Carlsbad, CA, USA) according to the manufacturer's instructions and tested in the PCR as it was presumed that the primer set designed would be effective for investigating the distribution of Solirubrobacterales strains. Specific bands were detected in $31(70 \%)$ of 44 soil samples by PCR (Figure 1-(1) and Figure 2, and Table 1). This result suggests that, although these are thought to be rare bacterial strains, they are widely distributed in soil. To confirm that these DNA fragments originated from target bacterial genomes, amplified DNA from soil sample no. 2, 3 and 5 was cloned using TOPO TA Cloning Kit (Invitrogen, Carlsbad, CA, USA) and extracted using PureLink Quick Plasmid Miniprep Kit (Invitrogen) according to the manufacturer's instructions. DNA fragments were purified using a QIAquick Gel Extraction Kit (Qiagen, Hilden, Germany) and sequenced using a 3130 Genetic Analyser (Applied Biosystems, Carlsbad, CA, USA). Sequences of seven clones from sample no. 2, 


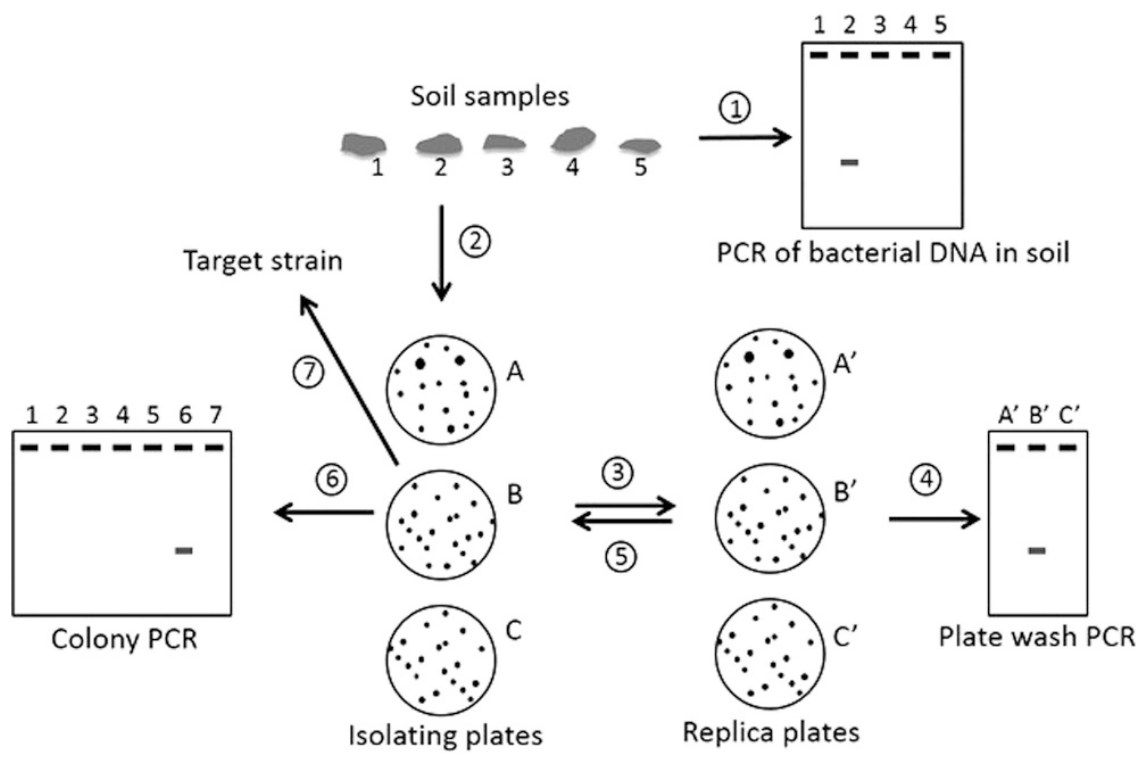

Figure 1 Strategy for distribution and isolation of order Solirubrobacterales strains. (1) Detection of target DNA fragments by specific primers, (2) isolation of bacteria from selected soil sample, (3) preparation of replica plates, (4) detection from all colonies on replica plate (Plate wash PCR), (5) selection of isolating plate, (6) detection of target colony (Colony PCR), (7) isolation of target strain (order Solirubrobacterales strain).

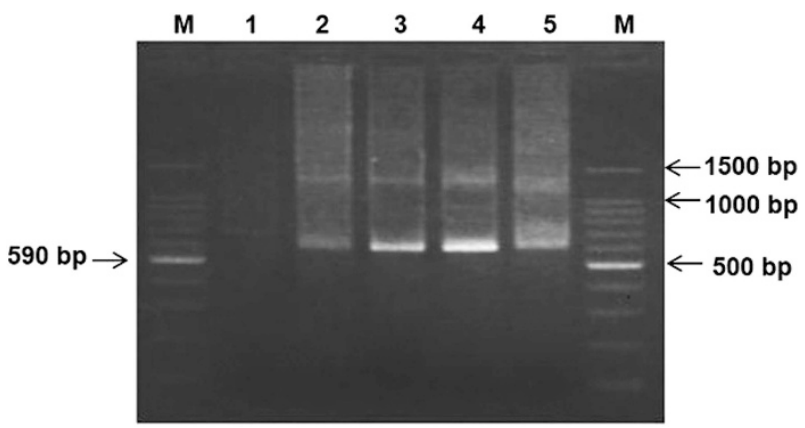

Figure 2 Detection of target DNA fragment from bacterial DNA of soil samples. Lane M: DNA marker. Lane 1: soil sample no. 1 from hill, Tokyo. Lane 2: soil sample no. 2 from field, Saitama prefecture. Lane 3: soil sample no. 3 from rice field, Saitama prefecture. Lane 4: soil sample no. 4 from forest, Saitama prefecture. Lane 5: soil sample no. 5 from sandy beach, Chiba prefecture

seven clones from no. 3 and six clones from no. 5 were analyzed and compared with two databases, DDBJ (http://blast.ddbj.nig.ac.jp/blastn? lang $=\mathrm{ja}$ ) to find the related species and EzTaxon (http://www. ezbiocloud.net/eztaxon/identify) to identify the most closely validly recognized species (Table 2). The sequences have been deposited in DDBJ under accession numbers LC015776-LC015795. All of the clones were found to have highest similarities with the genera Solirubrobacter or Conexibacter strains in the order Solirubrobacterales (93.6 to $99.4 \%$ ). Clones that were closest to C. woesei DSM $14684^{\mathrm{T}}$ were detected in all soil samples. The amplified genes were confirmed to have originated from microorganisms related to the order Solirubrobacterales strains. Therefore, we next attempted to isolate bacterial strains from the soil sample collected from the field in Saitama Prefecture (sample no. 2 in Table 1 and Figure 2).

Isolation was carried out by a combination of Plate wash PCR using the previously described Stevenson procedure ${ }^{14}$ with modifications and colony PCR. One gram of soil sample was serially diluted $\left(10^{-1}-10^{-4}\right)$ and $100 \mu \mathrm{l}$ of diluted samples were spread on
Table 1 Detection of target DNA from soil using specific primers

\begin{tabular}{lccc}
\hline Source of soil sample & $\begin{array}{c}\text { Number of } \\
\text { samples }\end{array}$ & $\begin{array}{c}\text { Number of positive } \\
\text { samples }\end{array}$ & Ratio (\%) \\
\hline Agricultural land & 11 & 7 & 64 \\
Waterside & 9 & 9 & 100 \\
Under the trees & 7 & 4 & 57 \\
Others & 17 & 11 & 65 \\
Total & 44 & 31 & 70 \\
\hline
\end{tabular}

Agricultural land; rice field, field and fruit farm.

Waterside; sandy beach and around the lake.

Under the trees; under the tree exclude grove soil.

Others; track, rangeland, sidewalk, mountain path, botanical garden, grove, cemetery, flowerbed, sand in park, thicket, shrine and park.

1/5 strength nutrient agar (1/5 NA; Difco, Detroit, MI, USA) plates containing benlate $\left(20 \mu \mathrm{g} \mathrm{ml}^{-1}\right.$; DuPont, Wilmington, DE, USA). Isolating plates were incubated at $27^{\circ} \mathrm{C}$ for 20 days (Figure 1-(2) and replica plates were made for each (Figure 1-(3). Colonies grown on the replica plates for 9 days were collected into $500 \mu$ sterile $\mathrm{dH}_{2} \mathrm{O}$ using a cell scraper with modified Stevenson's method ${ }^{14}$ (Figure 1-(4). The cells were then washed twice with TE buffer $(10 \mathrm{mM}$ Tris- $\mathrm{HCl}$, EDTA/2Na) with centrifugation at 7000 r.p.m. for $5 \mathrm{~min}$, and suspended in $500 \mu \mathrm{l}$ TE buffer. DNA extraction was performed by ultrasonic fragmentation according to the method of Yu et al. ${ }^{15}$ Target DNA fragments were detected from only one $\left(10^{-4}\right.$ diluted $)$ of the replica plates. Then, colony PCR was performed for all 91 colonies on the original isolating plate (Figure 1-(5) and (6)). Target DNA fragments were detected in seven colonies and the specific fragment sequences of these colonies were then analyzed. Five of these colonies were found to be closest to $P$. minatonensis $\mathrm{KV}-614^{\mathrm{T}}$ with similarities of 98.5 to $100 \%$. Two of the seven colonies, KV-962 and KV-963, were closest to C. woesei DSM $14684^{\mathrm{T}}$ ( $98.3 \%$ similarity). Taxonomic studies of the two strains were carried out as the 16S rRNA gene sequences of KV-962 (accession no. AB597950) and KV-963 (accession no. AB597951) showed low similarity with those of C. woesei DSM 
Table 2 The closely matched species based on DNA sequences cloned from amplified fragments

\begin{tabular}{|c|c|c|c|c|c|}
\hline Soil no. & Clone no. & Length of sequence & Accession no. & Closest match in EzTaxon database & Closest match in DDBJ database \\
\hline \multirow{7}{*}{2} & 1 & 506 & LC015776 & Solirubrobacter phytolaccae GTGR-8' (99.4) & Solirubrobacter sp. L64, FJ459990 (99.8) \\
\hline & 2 & 534 & LC015777 & Solirubrobacter ginsenosidimutans BXN5-15 (98.9) & Solirubrobacter sp. L64, FJ459990 (99.8) \\
\hline & 3 & 536 & LCO15778 & Solirubrobacter ginsenosidimutans BXN5-15 (99.3) & Solirubrobacter sp. L64, FJ459990 (99.3) \\
\hline & 4 & 492 & LC015779 & Solirubrobacter phytolaccae GTGR-8 ${ }^{\top}$ (96.5) & Solirubrobacter sp. L64, FJ459990 (97.9) \\
\hline & 5 & 507 & LC015780 & Solirubrobacter ginsenosidimutans BXN5-15 $5^{\top}$ (99.2) & Solirubrobacter sp. L64, FJ459990 (99.8) \\
\hline & 6 & 536 & LC015781 & Conexibacter woesei DSM $14684^{\top}(96.6)$ & Conexibacter sp. BS10, JF806520 (98.0) \\
\hline & 7 & 557 & LC015782 & Conexibacter woesei DSM $14684^{\top}(97.1)$ & Bacterium Ellin504, AY960767 (97.5) \\
\hline \multirow{7}{*}{3} & 8 & 542 & LC015783 & Conexibacter woesei DSM $14684^{\top}(94.8)$ & Conexibacter woesei DSM $14684^{\top}$, CP001854 (95.3) \\
\hline & 9 & 528 & LC015784 & Conexibacter woesei DSM $14684^{\top}$ (95.3) & Conexibacter woesei DSM $14684^{\top}$, CP001854 (95.7) \\
\hline & 10 & 531 & LC015785 & Conexibacter woesei DSM $14684^{\top}$ (95.3) & Conexibacter woesei DSM $14684^{\top}$, CP001854 (95.7) \\
\hline & 11 & 536 & LC015786 & Conexibacter woesei DSM $14684^{\top}$ (95.0) & Conexibacter woesei DSM $14684^{\top}$, CP001854 (95.4) \\
\hline & 12 & 534 & LC015787 & Conexibacter woesei DSM $14684^{\top}$ (95.3) & Conexibacter woesei DSM $14684^{\top}$, CP001854 (95.6) \\
\hline & 13 & 531 & LC015788 & Conexibacter woesei DSM $14684^{\top}$ (95.3) & Conexibacter woesei DSM $14684^{\top}$, CP001854 (95.8) \\
\hline & 14 & 560 & LC015789 & Conexibacter woesei DSM $14684^{\top}$ (93.6) & Bacterium Ellin325, AF498707 (96.3) \\
\hline \multirow{6}{*}{5} & 15 & 557 & LC015790 & Solirubrobacter ginsenosidimutans BXN5-15 (98.2) & Solirubrobacter sp. L64, FJ459990 (99.8) \\
\hline & 16 & 490 & LC015791 & Solirubrobacter ginsenosidimutans BXN5-15 $5^{\top}$ (97.8) & Solirubrobacter sp. L64, FJ459990 (98.7) \\
\hline & 17 & 555 & LC015792 & Conexibacter woesei DSM $14684^{\top}(94.8)$ & Bacterium Ellin504, AY960767 (97.3) \\
\hline & 18 & 526 & LC015793 & Conexibacter woesei DSM $14684^{\top}(94.7)$ & Bacterium Ellin504, AY960767 (97.2) \\
\hline & 19 & 554 & LC015794 & Conexibacter woesei DSM $14684^{\top}$ (94.9) & bacterium Ellin504, AY960767 (97.3) \\
\hline & 20 & 513 & LC015795 & Solirubrobacter phytolaccae GTGR-8 ${ }^{\top}$ (97.0) & Conexibacter arvalis KV-962 ${ }^{\top}$ AB597950 (97.4) \\
\hline
\end{tabular}

The values within parentheses () represents similarity percentage of closest strain.

Soil sample number is same as the number mentioned in Figure 2.

$14684^{\mathrm{T}}$, and they were proposed as a new species of Conexibacter and C. arvalis. ${ }^{16} \mathrm{KV}-962$ and $\mathrm{KV}-963$ were isolated from the soil samples from which clones no. 6 and no. 7 originated. The similarity values between these two isolates and two clones were 97.1-98.0\%. The similarity values are not so high. This means that more related strains exist in this sample.

The order Solirubrobacterales is presently composed of only three genera containing 11 species. DNA fragments of strains belonging to the order Solirubrobacterales were detected from all prefectures examined (Data are not shown). This result indicates that they are cosmopolitan. According to isolation conditions, it is possible to isolate them more frequently. Especially, samples from waterside showed high rate of target DNA fragments (Table 1). Waterside may be suitable to inhabit as these strains have motility. We succeeded to isolate them using 1/5 NA by a combination of Plate wash PCR. These results show that bacterial strains belonging to the order Solirubrobacterales are widely found living in the soil.

P. minatonensis $\mathrm{KV}-614^{\mathrm{T}}$ was isolated using a medium supplemented with SOD to remove oxygen species generated from nutrient agar. ${ }^{17}$ Therefore, we used $1 / 5$ NA for suppression of superoxide. $P$. ginsengiterrae $\mathrm{P} 4-5^{\mathrm{T}}$ was isolated using $1 / 10 \mathrm{NA},{ }^{18}$ and $\mathrm{R} 2 \mathrm{~A}$ agar was used for isolation of S. soli and S. phytilica. ${ }^{19,20}$ These data show that nutritionally poor media are effective for isolation of Solirubrobacterales strains. Our clone library analyses in Table 2 indicated that the gene sequences are related to strains Ellin 325 or Ellin 504, which were originally isolated using nutritionally poor medium after cultivation for 3-6 months. ${ }^{21,22}$ Although these isolates were isolated using poor media, it is unclear whether they are sensitive to reactive oxygen.

We expect that we will be able to obtain many as-yet-uncultured bacteria as untapped resources from the environment using new ideas for isolating and cultivating.

\section{ACKNOWLEDGEMENTS}

We are grateful to Dr Akiko Kageyama for designing specific primers and Mr Katsuhito Yamazaki for help with the experiment.

1 Whitman, W. B., Coleman, D. C. \& Wiebe, W. J. Prokaryotes: the unseen majority. Proc Natl Acad. Sci. USA 95, 6578-6583 (1998).

2 Hugenholtz, P. Exploring prokaryotic diversity in the genomic era. Genome Biol. 3: reviews0003.1-0003.8 (2002).

3 Davis, E. R. K., Joseph, J. S. \& Janssen, H. P. Effects of growth medium, inoculum size, and incubation time on culturability and isolation of soil bacteria. Appl. Environ. Microbiol. 71, 826-834 (2005).

4 Takahashi, Y., Matsumoto, A., Morisaki, K. \& Ōmura, S. Patulibacter minatonensis gen. nov., sp. nov., a novel actinobacterium isolated using an agar medium supplemented with superoxide dismutase, and proposal of Patulibacteraceae fam. nov. Int. J. Syst. Evol. Microbiol. 56, 401-406 (2006).

5 Reddy, G. S. N. \& Garcia-Pichel, F. Description of Patulibacter americanus sp. nov., isolated from biological soil crusts, emended description of the genus Patulibacter Takahashi et al. 2006 and proposal of Solirubrobacterales ord. nov. and Thermoleophilales ord. nov. Int. J. Syst. Evol. Microbiol. 59, 87-94 (2009).

6 Monciardini, P., Cavaletti, L., Schumann, P., Rohde, M. \& Donadio, S. Conexibacter woesei gen. nov., sp. nov., a novel representative of a deep evolutionary line of descent within the class Actinobacteria. Int. J. Syst. Evol. Microbiol. 53, 569-576 (2003).

7 Singleton, D. R. et al. Solirubrobacter pauli gen. nov., sp. nov., a mesophilic bacterium within the Rubrobacteridae related to common soil clones. Int. J. Syst. Evol. Microbiol. 53, 485-490 (2003)

8 Suzuki, K., Collins, M. D., lijima, E. \& Komagata, K. Chemotaxonomic characterization of a radiotolerant bacterium, Arthrobacter radiotolerans: description of Rubrobacter radiotolerans gen. nov., comb. nov. FEMS Microbiol. Lett. 52, 33-40 (1988).

9 Chen, M. Y. et al. Rubrobacter taiwanensis sp. nov., a novel thermophilic, radiation-resistant species isolated from hot springs. Int. J. Syst. Evol. Microbiol. 54, 1849-1855 (2004).

10 Carreto, L. et al. Rubrobacter xylanophilus sp. nov., a new thermophilic species isolated from a thermally polluted effluent. Int. J. Syst. Bacteriol. 46, 460-465 (1996).

11 Sung, M.-H. et al. Symbiobacterium toebii sp. nov., commensal thermophile isolated from korean compost. J. Microbiol. Biotechnol. 13, 1013-1017 (2003).

12 Zarilla, K. A. \& Perry, J. J. Thermoleophilum album gen. nov. and sp. nov., a bacterium obligate for thermophily and $n$-alkane substrates. Arch. Microbiol. 137, 286-290 (1984). 
13 Zarilla, K. A. \& Perry, J. J. Deoxyribonucleic acid homology and othe comparisons among obligately thermophilic hydrocarbonoclastic bacteria, with proposal for Thermoleophilum minutum sp. nov. Int. J. Syst. Evol. Microbiol. 36, 13-16 (1986).

14 Stevenson, B. S., Eichorst, S. A., Wertz, J. T., Schmidt, T. M. \& Breznak, J. A. New strategies for cultivation and detection of previously uncultured microbes. Appl. Environ. Microbiol. 70, 4748-4755 (2004).

$15 \mathrm{Yu}$, L. et al. Application of PCR for selection of gram-positive bacteria with high DNA $\mathrm{G}+\mathrm{C}$ content among new isolates. Actinomycetol 16, 1-5 (2002).

16 Seki, T. et al. Conexibacter arvalis sp. nov., isolated from a cultivated field soil sample. Int. J. Syst. Evol. Microbiol. 62, 2400-2404 (2012).

17 Nakashima, T. et al. Generation of reactive oxygen species from conventional laboratory media. J. Biosci. Bioeng. 110, 304-307 (2010).
18 Kim, K. K., Lee, K. C. \& Lee, J.-S. Patulibacter ginsengiterrae sp. nov., isolated from soil of a ginseng field, and an emended description of the genus Patulibacter. Int. J. Syst. Evol. Microbiol. 62, 563-568 (2012).

$19 \mathrm{Kim}$, M. K. et al. Solirubrobacter soli sp. nov., isolated from soil of a ginseng field. Int. J. Syst. Evol. Microbiol. 57, 1453-1455 (2007).

20 Wei, L., Ouyang, S., Wang, Y., Shen, X. \& Zhang, L. Solirubrobacter phytolaccae sp. nov., an endophytic bacterium isolated from roots of Phytolacca acinosa Roxb. Int. J. Syst. Evol. Microbiol. 64, 858-862 (2014).

21 Sait, M., Hugenholtz, P. \& Janssen, P. H. Cultivation of globally distributed soil bacteria from phylogenetic lineages previously only detected in cultivation-independent surveys. Environ. Microbiol. 4, 654-666 (2002).

22 Sangwan, P., Kavac, S., Davis, K. E. R., Sait, M. \& Janssen, P. H. Detection and cultivation of soil Verrucomicrobia. Appl. Environ. Microbiol. 71, 8402-8410 (2005) 